\title{
Distribuição horizontal da fertilidade do solo em sistemas de tráfego controlado com fertilização em linha
}

\author{
Anderson LANGE ${ }^{1 *}$, Rodrigo Sinaidi ZANDONADI ${ }^{1}$, Fernando Cesar GOBBI ${ }^{2}$ \\ ${ }^{1}$ Instituto de Ciências Agrárias e Ambientais, Universidade Federal de Mato Grosso, Sinop, MT, Brasil. \\ ${ }^{2}$ Fazenda Gobbi, Tabaporã, MT, Brasil. \\ *E-mail: paranalange@hotmail.com
}

Recebido em novembro/2018; Aceito em fevereiro/2019.

\begin{abstract}
RESUMO: Tendo em vista a variabilidade do solo em sistemas de semeadura direta, as dificuldades encontradas pelos produtores em amostrar corretamente o solo principalmente em operações em que se usa o tráfego controlado, o objetivo do trabalho foi avaliar o perfil de distribuição horizontal da fertilidade do solo em torno da linha de semeadura em sistema de produção de soja utilizando a mesma pista de semeadura em sistema de tráfego controlado. Em fevereiro de 2017, após a colheita da soja, em um talhão que os últimos 5 anos se usou a mesma pista de semeadura, o solo foi amostrado sobre a linha de semeadura/fertilização, a 8, 16 e $25 \mathrm{~cm}$ (para ambos os lados), na camada de $0-20 \mathrm{~cm}$, num total de seis repetições. Os resultados mostram que há concentração de alguns nutrientes na linha de deposição, principalmente o $\mathrm{P}$, que é um fator altamente positivo, pois reduz a fixação deste elemento. Existe também a acidificação da linha de semeadura devido aos fertilizantes nitrogenados, extração/exportação de cátions e balanço eletroquímico que a planta realiza. Assim recomenda-se observar atentamente o método de adubação da propriedade para definir a melhor estratégia de amostragem de solo, desta forma evitando equívocos de interpretação nos resultados analíticos.
\end{abstract}

Palavras-chave: amostragem de solo, agricultura de precisão, fósforo.

\section{Horizontal distribution of soil fertility in controlled traffic farming planting operation with row fertilization}

\begin{abstract}
Considering the soil variability in no-till system, along with the difficulties encountered by the producers regarding soil sampling strategies, especially in the Controlled Traffic Farming setup where same furrow can be used year after year; the objective of the work was to evaluate soil fertility horizontal profile across the furrow. In February 2017, after the soybean harvest, data was collected in a farm where soybean plating has been taken place using same furrow for at least 5 years. Soil was sampled $(0-20 \mathrm{~cm}$ layer $)$ at the furrow and at 8,16 and $25 \mathrm{~cm}$ for both sides. A total of six replicates (six different furrows in the field) was collected. The results showed that there is concentration of some nutrients in furrow, mainly $\mathrm{P}$, which is a good aspect, because it reduces the fixation of this element. Therefore, the sampling strategy (furrow + with in the row), is important, independent of the use of precision agriculture (AP) or grids because it can hamper the interpretation of the analytical results, leading in erroneous recommendations. Thus, it is recommended to carefully observe the fertilization method used to define the best soil sampling strategy, thus avoiding misunderstandings in the analytical results.
\end{abstract}

Keywords: soil sampling, precision agriculture, phosphorus.

\section{INTRODUÇÃO}

Nas últimas décadas a agricultura brasileira tem buscado técnicas que possibilitem a diminuição da degradação dos solos, contribuindo para a melhoria do meio e garantindo o aumento da produtividade das grandes culturas. Neste sentido, podemos destacar o Sistema Semeadura Direta (SSD).

Já é sabido que a sua adoção modificou os atributos químicos, físicos e biológicos do solo em relação ao preparo convencional. Diversos trabalhos documentam esta evolução no qual o SSD aumenta a concentração de nutrientes na superfície do solo, ocorrendo tanto variabilidade horizontal e vertical (MUZILLI, 1983; ELTZ et al., 1989). Mais recentemente Sousa et al. (2016) verificaram que tanto a adubação na linha de semeadura como lanço em SSD, após longo tempo de utilização das duas diferentes práticas, o perfil do solo se assemelha abaixo de $10 \mathrm{~cm}$, porém com maior acúmulo para a adubação a lanço superficialmente em relação à linha.

Devido ao não revolvimento do solo, a concentração de nutrientes, principalmente de $\mathrm{P}$, tende a elevar-se na camada superficial do solo ano após ano. Isto ocorre porque o processo de fixação, em virtude do não revolvimento, concentra o $\mathrm{P}$ superficialmente em bandas no fundo do sulco de adubação, onde foi colocado, formando um horizonte saturado. Além disso, a decomposição gradual dos resíduos proporciona a liberação e redistribuição de formas orgânicas de $\mathrm{P}$ mais estáveis e menos susceptíveis às reações de adsorção (SÁ, 1996), o que concentra $P$ na camada superficial. O mesmo autor, em levantamento de áreas com até 15 anos em SSD no Estado do Paraná observou que a camada superficial $(0-10 \mathrm{~cm})$ continha elevado teor de $\mathrm{P}$, com cerca de $88 \%$ do total de $\mathrm{P}$ disponível observado na camada $0-30 \mathrm{~cm}$. Desse modo, a 
disponibilidade de $\mathrm{P}$ tende a ser maior em SSD, podendo inclusive influenciar na nutrição das culturas.

A metodologia de amostragem do solo em SSD preconizada por alguns boletins consiste em abrir uma trincheira após a colheita da cultura principal abrangendo linha mais metade do espaçamento da entrelinha da cultura anterior para ambos os lados, na profundidade desejada e coletar uma fatia de solo (CFSMG, 1999), favorecendo assim a diluição do fertilizante residual da cultura anterior e melhor representando a fertilidade real do solo. Com o objetivo facilitar a amostragem em áreas de SSD, desenvolveu-se um estudo com as culturas do trigo, soja e milho em lavouras sob SSD consolidado e verificou-se que a coleta com sonda pode ser utilizada, sendo que o número de pontos amostrados depende da cultura antecessora, já que a amostragem em SSD contempla furos sobre a última linha de semeadura e na entrelinha, para assim encontrar o efeito residual do fertilizante da cultura anterior (NICOLODI et al., 2002). Apesar dos esforços que alguns autores têm realizado para determinar a melhor forma de amostragem em SSD, ainda se peca em qual o ponto correto para amostragem em função do manejo de aplicação de fertilizantes pelo produtor.

O uso da adubação antecipada, em pré-semeadura por sistemas de distribuição em superfície, sendo o mais comum o sistema de distribuição a lanço tem sido largamente utilizado no Cerrado. Essa prática tem se tornado comum, principalmente devido a característica de permitir maior capacidade operacional na operação de semeadura. Apesar da prática da adubação antecipada ter se tornado relativamente comum, principalmente no Mato Grosso, muito se discute ainda sobre a eficiência desse sistema em relação as outras de técnicas de adubação. Tratando-se do fósforo, as divergências são ainda maiores e faltam estudos em diferentes condições de solo, clima, sistemas de produção e formas de aplicação do P no solo.

De acordo com Sousa et al. (2016), em trabalho clássico conduzido por 17 anos, com cultivos de soja e milho, o resultado final foi uma produção acumulada de $97,8 \mathrm{t} \mathrm{ha}^{-1} \mathrm{e}$ $96,6 \mathrm{t} \mathrm{ha}^{-1}$, para aplicação a lanço na superfície do solo e no sulco de semeadura, demonstrando que ao longo do tempo, os sistemas se equiparam. A aplicação a lanço na superfície do solo resultou em menor produtividade nos dois primeiros anos de cultivo, segundos os autores, em relação ao sulco, porque o acesso das raízes ao $\mathrm{P}$ superficial pode ter sido limitado, porém ao longo dos anos o efeito desaparece. Por isso não se recomenda a adubação superficial em SSD até o sistema estar estabilizado. Os autores também observaram movimentação vertical de $\mathrm{P}$ até a profundidade de $10 \mathrm{~cm}$, mesmo aplicado na superfície, possivelmente devido ao distúrbio mecânico do solo na operação de semeadura e à mineralização do $\mathrm{P}$ contido nas raízes, atingindo concentrações no solo que foram suficientes para o adequado crescimento radicular.

Mais recentemente com o advento da Agricultura de Precisão (AP), tem-se amostrado o solo, buscando determinar sua fertilidade, na forma de grades amostrais (2 a 10 ha) e assim gerando mapas de fertilidade para fins de recomendação para aplicação à taxa variável. Eletrônica embarcada e GNSS (Sistema de Navegação Global por Satélite) compondo sistemas de direcionamento automáticos em máquinas agrícolas permitiram a implementação do Controle de Tráfego de Máquinas (CTM) durante as operações agrícolas.

Em sistemas de CTM, busca-se minimizar compactação do solo e otimizar rota de máquinas (RAPER, 2005;
ZANDONADI, 2012). Além do mencionado previamente, em revisão conduzida por Gasso et al. (2013), relatos de redução em: emissão de gases, uso de fertilizantes, pesticidas, sementes e combustível, são apontados pelo uso de CTM nas operações agrícolas.

Utilizando as técnicas de tráfego controlado, é possível optar por utilizar sempre a mesma pista de semeadura fazendo com que as linhas de deposição da semente e fertilizante sejam as mesmas todos os anos, formando assim um ambiente rico em relação aos nutrientes ali aplicados, o que pode ocasionar uma concentração horizontal de $\mathrm{P}$ em pistas fixas.

Diante do exposto, vários produtores do estado de Mato Grosso optam por continuar com a prática da adubação em linha na operação de semeadura de soja e milho, muitas vezes utilizando inclusive hastes sulcadoras, ao invés de discos sulcadores. Este cenário associado ao uso do tráfego controlado nas operações agrícolas impõe certa dificuldade em relação as estratégias de amostragem de solo. Porém o entendimento do perfil de distribuição horizontal da fertilidade do solo, poderá nortear estratégias de amostragem e inclusive desenvolvimento de equipamentos e sistemas que facilitem o processo e proporcionem uma amostragem de solo mais representativa.

Dessa maneira, o objetivo do trabalho foi avaliar o perfil de distribuição horizontal da fertilidade do solo em torno da linha de semeadura em sistema de produção de soja utilizando a mesma pista de semeadura em sistema de tráfego controlado.

\section{MATERIAL E MÉTODOS}

O experimento foi instalado na fazenda Gobbi (Tabaporã, MT), na safra 2016/17. Selecionou-se um talhão de fertilidade construída, com mais de 10 anos de uso agrícola, no qual o produtor vem utilizando a mesma pista para a semeadura da cultura da soja a 5 anos, aplicando anualmente cerca de 15 a $20 \mathrm{~kg} \mathrm{ha}^{-1}$ de $\mathrm{N}, 80$ a $120 \mathrm{~kg} \mathrm{ha}^{-1}$ de $_{2} \mathrm{O}_{5}$ e 100 a $120 \mathrm{~kg} \mathrm{ha}^{-1}$ de $\mathrm{K}_{2} \mathrm{O}$ na soja, sendo o $\mathrm{P}$ sempre aplicado em linha na operação de semeadura e o K, ora linha ora superficie, em área total.

Após a colheita da soja, em fevereiro de 2017, semeada no espaçamento de $50 \mathrm{~cm}$ entrelinhas, foram coletadas amostras de solo na profundidade de $0-20 \mathrm{~cm}$, com sonda, em diferentes posições em relação a linha de semeadura, a saber: sobre a linha, a 8 , a 16 e a $25 \mathrm{~cm}$ para ambos os lados da linha central (direita e esquerda), configurando assim 7 pontos amostrais ou 7 tratamentos, retirando dois furos, lado a lado por ponto para melhor representar a subamostra (Figura 1).

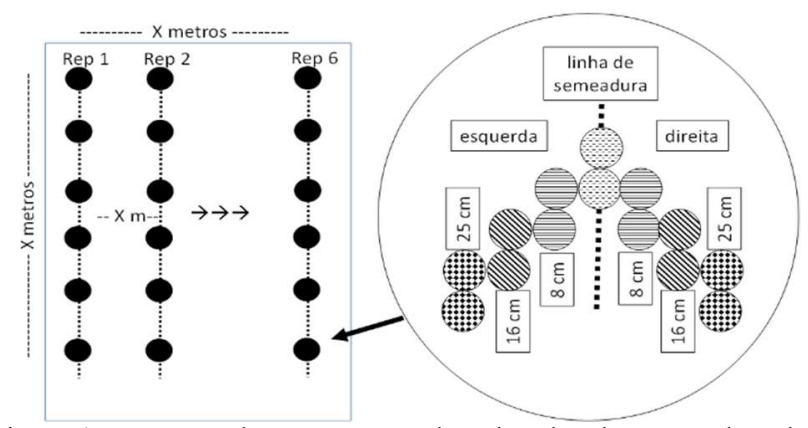

Figura 1. Esquema de amostragem de solo adotado para coleta de amostras em diferentes posições em relação a linha de deposição dos fertilizantes e sementes.

Figure 1. Soil sampling schemed used collecting soil samples at different position with respect to the row of seed and fertilizer deposition. 
Para a coleta, adotou-se um caminhamento acompanhando uma linha de semeadura escolhida aleatoriamente, colhendose 6 pontos ao longo de 100 metros, num total de 12 furos, para a composição da amostra composta, configurando a $1^{\mathrm{a}}$ repetição. Nas demais repetições, escolheu-se a mesma linha da semeadora, no sentido de retorno desta no talhão, num total de 6 repetições.

As amostras de solo coletadas foram analisadas em laboratório comercial, em Botucatu - SP, sendo determinados fósforo, potássio, cálcio e magnésio pela extração com resina, acidez total pelo método SMP, $\mathrm{pH}$ em $\mathrm{CaCl}_{2}$, boro, cobre, ferro, manganês e zinco pela extração com DTPA. Os resultados nas análises de solos foram submetidos à anova para análise de variância, aplicando-se teste de Scott Knott a 5\% de probabilidade, quando a variável foi significativa.

\section{RESULTADOS}

Os resultados das análises são apresentados a seguir sendo $\mathrm{P}, \mathrm{K}, \mathrm{Ca}$ e Mg (Figura 2), pH, H+Al, Capacidade de troca de cátions (C.T.C.), Soma das Bases (SB), Saturação por Bases (V\%) e \% de H na C.T.C. (Figura 3), Boro, Cobre, Manganês e Zinco, $\%$ de bases na C.T.C. e relações entre as bases (Figura 4). Os valores acompanhados de mesma letra para cada nutriente não apresentaram diferença significativa a 5\% de probabilidade. Os critérios para interpretação de saturação por elemento em função da saturação por bases (V\%) (Vitti; Vieira 2016) são apresentados na Tabela 1.
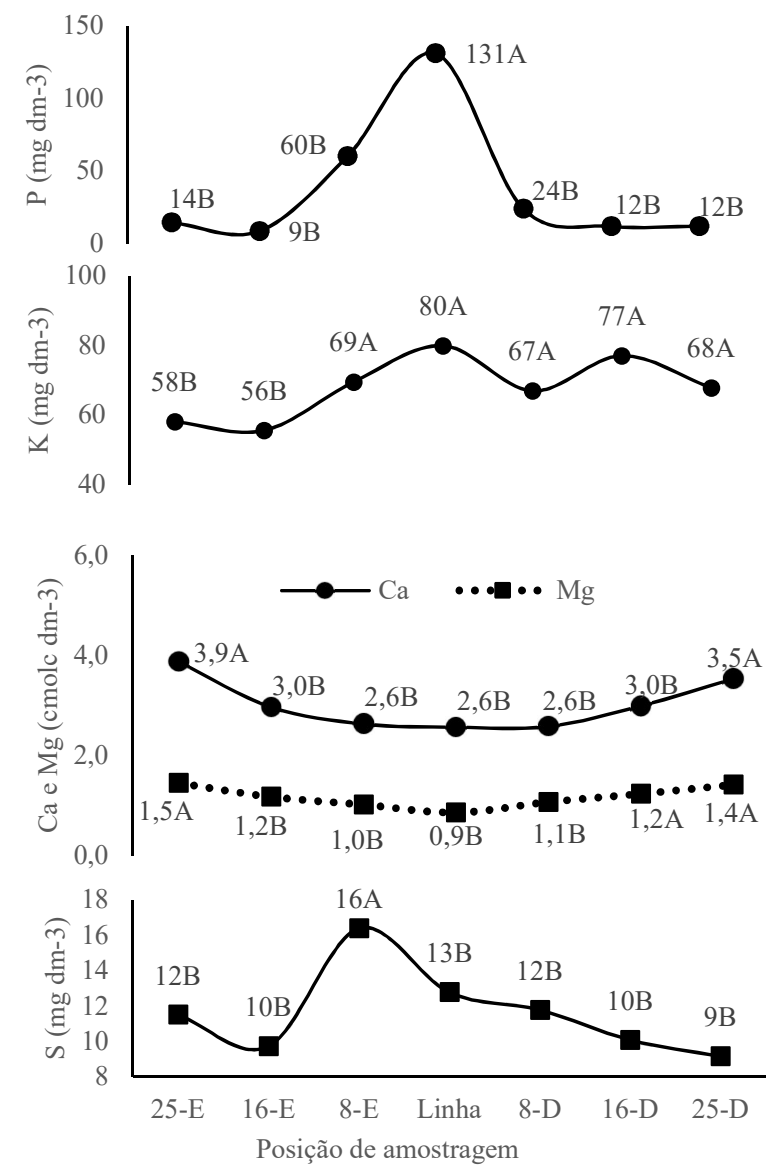

Figura 2. Perfil de distribuição dos teores dos macronutrientes fósforo $(\mathrm{P})$, potássio $(\mathrm{K})$, cálcio $(\mathrm{Ca})$, magnésio $(\mathrm{Mg})$ e enxofre $(\mathrm{S})$ em semeadura com fertilizante na linha utilizando CTM.

Figure 2. Macronutrients distribution profile for phosphorous (P), potassium $(\mathrm{K})$, calcium $(\mathrm{Ca})$, magnesium $(\mathrm{Mg})$ e sulfur(S) in planting operation with row fertilization using CTM.
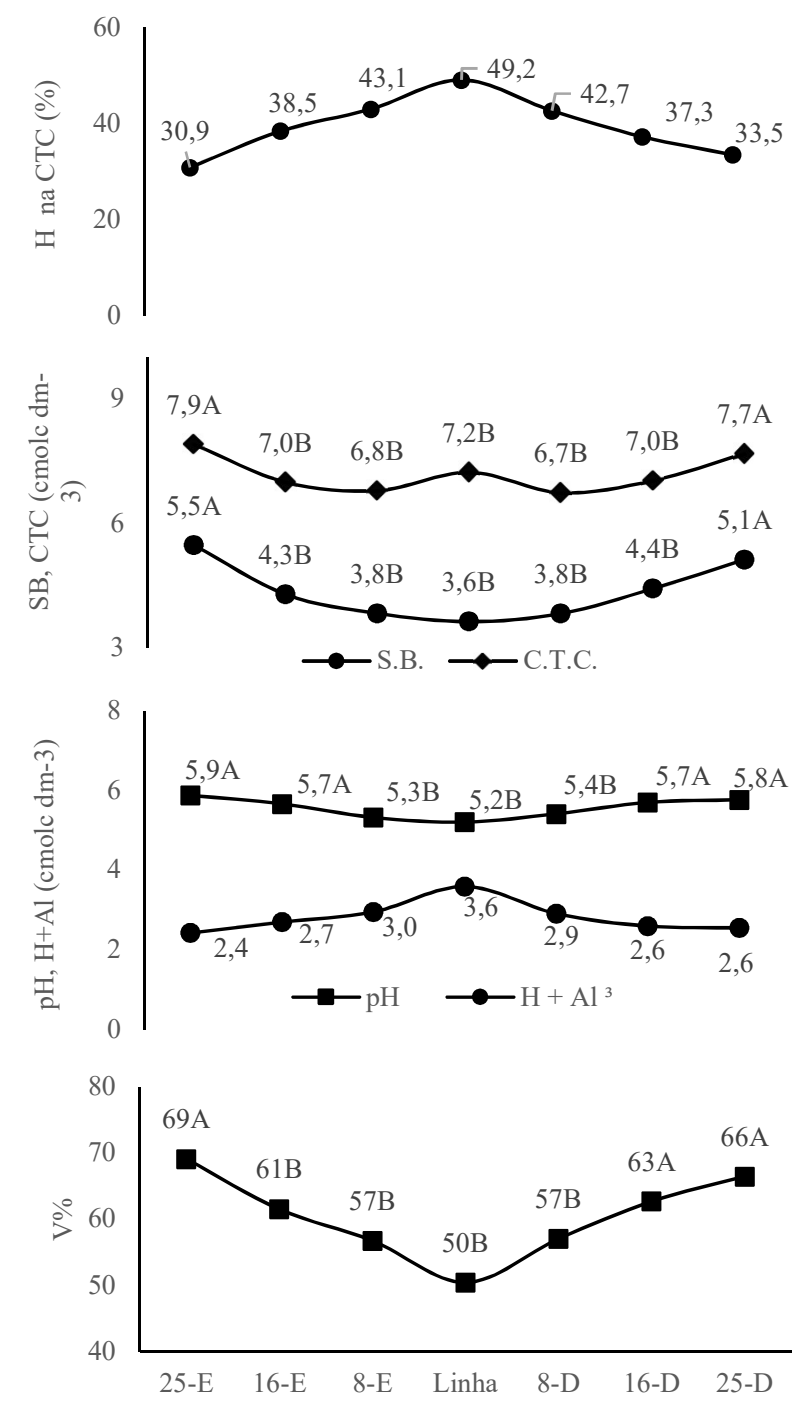

Figura 3. Perfil de distribuição da \% H na CTC, da Capacidade de troca de cátions (C.T.C.), Soma das Bases (SB), dos valores de $\mathrm{pH}$ e hidrogênio e alumínio $(\mathrm{H}+\mathrm{Al})$ e da Saturação por Bases (V\%) em semeadura com fertilizante na linha utilizando CTM.

Figure 3. Distribution profile for values of $\% \mathrm{H}$ at the CTC, Cation exchange capacity (CTC), sum of bases (SB), pH, hydrogen and aluminum $(\mathrm{H}+\mathrm{Al})$ and base saturation $(\mathrm{V} \%)$ in planting operation with row fertilization using CTM.

Tabela 1. Valores de interpretação da \% de saturação por Ca, $\mathrm{Mg}$ e K na CTC em função da saturação por bases $(\mathrm{V} \%)$ do solo.

Table 1. Interpretation table used for $\%$ saturation of $\mathrm{Ca}, \mathrm{Mg}$, and $\mathrm{K}$ at CTC according to soil base saturation ( $\mathrm{V} \%)$.

\begin{tabular}{lccc}
\hline $\mathrm{V} \%$ & $\mathrm{Ca}$ & $\mathrm{Mg}$ & $\mathrm{K}$ \\
\hline \multicolumn{4}{c}{$\%$ do elemento na CTC } \\
\hline 40,0 & $28,0-35,0$ & $9,0-11,0$ & $3,0-4,0$ \\
50,0 & $35,1-40,0$ & $11,1-15,0$ & $4,1-5,0$ \\
60,0 & $40,0-48,0$ & $15,1-16,0$ & $>5,1$ \\
\cline { 2 - 4 } 70,0 & $>48$ & $>16,0$ & $>5,1$ \\
\hline
\end{tabular}

Fonte: Vitti; Vieira (2016).

\section{DISCUSSÃO}

Verifica-se que houve alta concentração de fósforo $(\mathrm{P})$ sobre a linha de semeadura e de potássio $(\mathrm{K})$ em menor magnitude, e o contrário para $\mathrm{Ca}$ e $\mathrm{Mg}$, estes concentram-se nas entrelinhas (Figura 2). A explicação para $\mathrm{P}$ e $\mathrm{K}$ deve a aplicação destes nutrientes nos fertilizantes usados ao longo dos anos (02-18-18, 10-20-20, MAP), ou mesmo nos fertilizantes simples (superfosfato triplo, superfosfato simples) 
que são ano a ano aplicados sempre na mesma linha, criando uma zona de alta concentração dos mesmos. No caso do P, por este ser um elemento ser pouco móvel no solo, a zona fica bem mais nítida e os teores elevados, chegando a $131 \mathrm{mg} \mathrm{dm}^{-3} \mathrm{de}$ $\mathrm{P}$, valor este muito acima do nível crítico, que é próximo a 20 $\mathrm{mg} \mathrm{dm}^{-3}$, pelo método da resina trocadora de íons (Sousa et al., 2016), o que se traduz em alta produtividade de soja nestas áreas, com médias superiores a $4300 \mathrm{~kg} \mathrm{ha}^{-1}$.
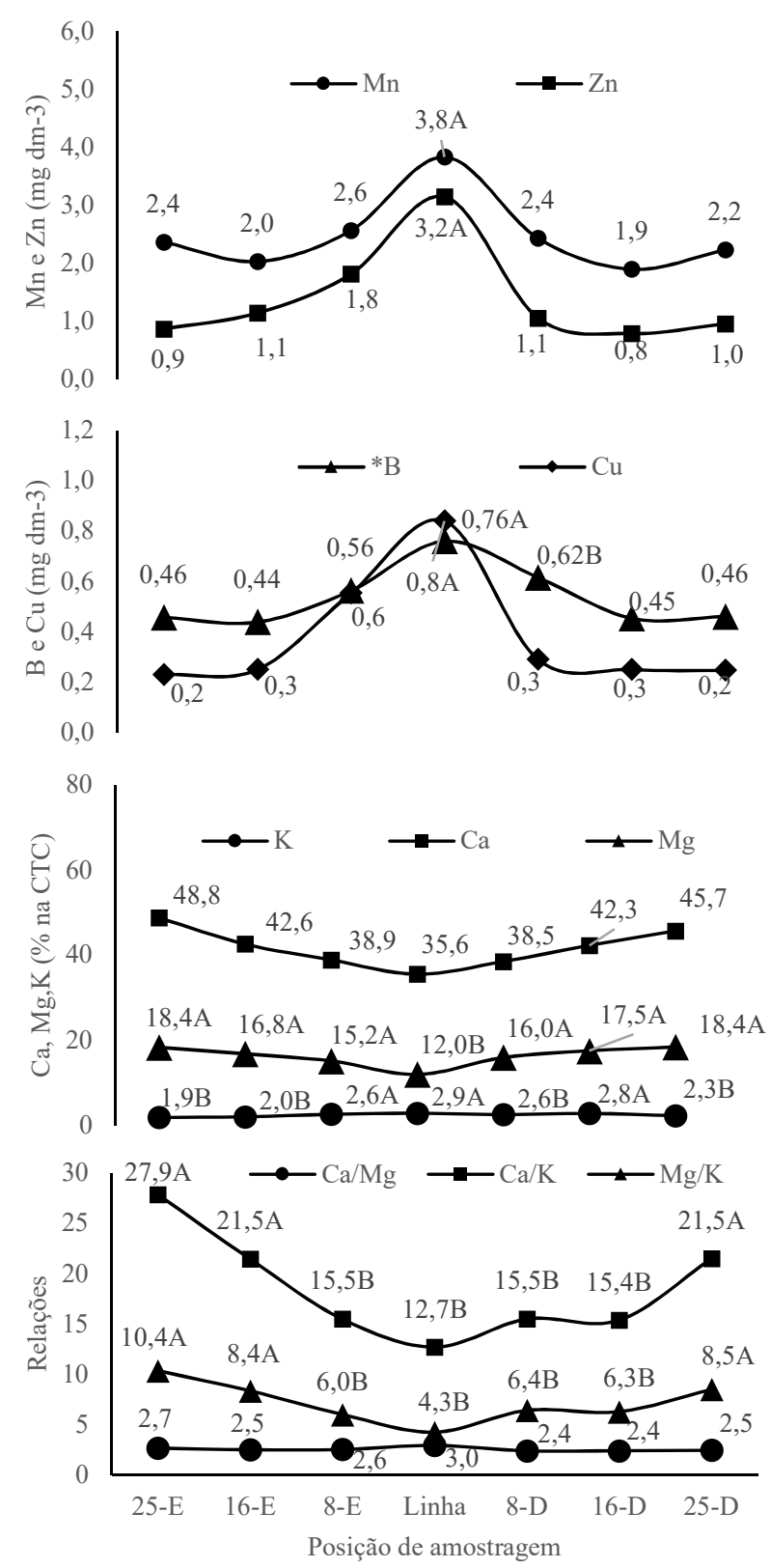

Figura 4. Perfil de distribuição dos teores de micronutrientes $(\mathrm{B}, \mathrm{Cu}$, $\mathrm{Mn}$ e $\mathrm{Zn}$ ), das saturações de $\mathrm{K}, \mathrm{Ca}$ e $\mathrm{Mg}$ na CTC (\%) e das relações $\mathrm{Ca} / \mathrm{Mg}, \mathrm{Ca} / \mathrm{K}$ e $\mathrm{Mg} / \mathrm{K}$ no complexo de troca em semeadura com fertilizante na linha utilizando CTM.

Figure 4. Distribution profile for macronutrients (B, Cu, Mn e $\mathrm{Zn}$ ), saturation of $\mathrm{K}, \mathrm{Ca}$ and $\mathrm{Mg}$ at $\mathrm{CTC}(\%)$, ratio $\mathrm{Ca} / \mathrm{Mg}, \mathrm{Ca} / \mathrm{K}$ and $\mathrm{Mg} / \mathrm{K}$ in planting operation with row fertilization using CTM.

Para o K, os teores apesar de elevados sobre a linha (80 mg $\mathrm{dm}^{-3}$ ), ficam mais bem distribuídos, o que é explicado pela mobilidade do elemento no solo, tanto vertical com horizontalmente, o que possivelmente também provocou movimentação vertical, fora da zona de amostragem. Outros fatores que contribuem para a melhor distribuição horizontal do especificamente para K no sistema são adubações a lanço que em determinadas situações são usadas no manejo da fazenda, diferente de $\mathrm{P}$, que é sempre aplicado apenas nas linhas, os restos culturas da soja, das plantas de cobertura e, principalmente do milho, que contém elevada quantidade de $\mathrm{K}$ na palha, até $160 \mathrm{~kg} \mathrm{ha}^{-1}$ (Cavalli et al., 2018), em sistema de alta produção como o avaliado o qual é distribuído por toda a superfície do solo, redistribuindo o K absorvido pela planta na linha para a camada superficial do solo.

Para o cálcio $(\mathrm{Ca})$ e magnésio $(\mathrm{Mg})$ os menores teores sobre as linhas devem-se a extração e exportação destes nutrientes, o que faz reduzir a concentração dos mesmos na zona de influência do sistema radicular, pois a aplicação de $\mathrm{Ca}$ e Mg se dá basicamente pelo uso de calcário, que é aplicado em área total, sobre a superfície do solo, de forma homogênea, não favorecendo a concentração em linha destes elementos, exceto quando se utiliza um fertilizante que tenha os mesmos como elementos secundários.

Outro fator favorável à menor concentração sobre a linha é a acidificação do solo (Figura 3), decorrente da aplicação de fertilizantes nitrogenados em algumas situações na soja, em pequenas doses, que acidificam o solo, reduzindo o $\mathrm{pH}$, além do balanço eletroquímico que a planta realiza, absorvendo cátions, como por exemplo o $\mathrm{Ca}^{2+}$ e exsudando também cátions, como $\mathrm{H}^{+}$, configurando uma zona ácida onde $\mathrm{o}$ sistema radicular se encontra ( $\mathrm{pH}$ baixo). A presença de $\mathrm{H}^{+}$no complexo de troca pode favorecer a movimentação vertical de $\mathrm{Ca}, \mathrm{Mg}$ e também de $\mathrm{K}$ no perfil do solo, por ocupar as cargas negativas do complexo de troca, como mostra a figura 3. Para o enxofre (S) a variação significativa $\left(16 \mathrm{mg} \mathrm{dm}^{-3}\right)$ ao lado esquerdo a $8 \mathrm{~cm}$, possivelmente ocorreu devido ao acaso, já que o elemento apresenta alta mobilidade no solo.

Os valores mais altos de $\mathrm{H}+\mathrm{Al}$ sobre a linha, apesar de não significativos, devem-se ao $\mathrm{pH}$ menor, como discutido, pois os teores de $\mathrm{Al}$ neste solo são praticamente iguais a zero, então a presença de íons $\mathrm{H}^{+}(<\mathrm{pH})$ resulta nesta acidificação, o que possivelmente interferiu também nos resultados de CTC do solo. O valor pontual de $7,2 \mathrm{cmol}_{\mathrm{c}} \mathrm{dm}^{-3}$ sobre a linha é decorrente da maior atividade dos ions $\mathrm{H}+$, já que o $\mathrm{Ca}$ e $\mathrm{Mg}$ foram menores sobre a linha. $\mathrm{O} \mathrm{K}$, apesar de superior na linha em termos numéricos, com $80 \mathrm{mg} \mathrm{dm}^{-3}$, a sua presença em termos percentuais na CTC é menor que 3\% (Figura 4), o que está de acordo com os resultados da soma das bases (SB) sobre a linha, com valores estatisticamente menores $\left(3,6 \mathrm{cmol}_{\mathrm{c}} \mathrm{dm}^{-}\right.$ ${ }^{3}$ ) em relação aos pontos do meio da linha, que apresentaram valores $>$ que $5,1 \mathrm{cmol}_{\mathrm{c}} \mathrm{dm}^{-3}$.

Nitidamente se observa então que a acidificação da zona radicular e a extração/exportação de $\mathrm{Ca}$ e $\mathrm{Mg}$ desta zona interferem na saturação por bases $(\mathrm{V} \%)$ do solo, com valores próximos a $50 \%$ sobre a linha e na entrelinha chegando a $66-$ $69 \%$, o que deve realmente ser atentado para um processo de amostragem de solo e de recomendação de calagem para este sistema de manejo. Assim, colher amostras apenas na entrelinha, desprezando os efeitos da adubação linear pode incorrer em erros amostrais e, consequente resultados de recomendações de calagem equivocados, em decorrência dos eventos que ocorrem sobre a linha dos fertilizantes, onde a planta se desenvolve.

Para os micronutrientes, o comportamento é similar ao $\mathrm{P}$, com uma mais zona rica sobre a linha para boro, cobre, manganês e zinco (Figura 4), decorrente a aplicação de adubos formulados enriquecidos em alguns anos com micronutrientes. 
Similarmente aos teores de $\mathrm{Ca}$ e $\mathrm{Mg}$ maiores nas entrelinhas, as saturações por estes nutrientes (\% de $\mathrm{Ca}$ e $\mathrm{Mg}$ na CTC) decaem na zona radicular, fruto da extração/exportação e também de uma possível movimentação no perfil, devido a acidez localizada. É importante ressalvar que a saturação por $\mathrm{Ca}$ é 13\% menor no centro, em valor absoluto igual a $35 \%$, o que é uma condição de baixa saturação, requerendo calagem e aumento do teor de $\mathrm{Ca}$ localizado, já na entrelinha, onde as raízes estão em menor concentração, os valores se aproximam de $50 \%$, considerado próximo ao adequado para as culturas (Furtini et al., 2001), não requerendo calagem. Isto também é visível para $\mathrm{Mg}$.

Percebe-se ao analisar a entrelinha, a $25 \mathrm{~cm}$ do centro, o $\mathrm{V} \%$ é próximo a $70 \%$, e as saturações de $\mathrm{Ca}$ e $\mathrm{Mg}$ estariam adequadas, já o $\mathrm{K}$ estaria restringindo a produtividade, conforme aponta Vitti e Vieira (2016) na tabela 1. Ao se analisar a linha de semeadura, o $\mathrm{V} \%$ é próximo a $50 \%$, novamente o $\mathrm{Ca}$ e $\mathrm{Mg}$ adequados segundo a tabela 1 e $\mathrm{K}$ baixo, porém o $\mathrm{V} \%$ é baixo para que se alcance altas produtividades, e manter o mesmo próximo a 70\% garante maiores índices produtivos, o que significa que os teores de $\mathrm{Ca}$ e $\mathrm{Mg}$ devem ser aumentados na linha de semeadura, por meio de uma aplicação localizada destes, se possível.

A aplicação localizada de calcário sobre a linha de semeadura, considerando sistemas de aplicação de fertilizante como aqui abordado, em pista fixa e tráfego controlado, melhoraria ainda mais a eficiência do uso dos fertilizantes pelas culturas, em especial para $\mathrm{P}$, pois é sabido com $\mathrm{o}$ aumento do $\mathrm{pH}$ do solo controla a disponibilidade da maioria dos nutrientes (FURTINI et al., 2001).

Outrossim, discordasse da literatura (Tabela 1) para as saturações de $\mathrm{K}$ recomendadas como ideais, as quais não se aplicam as condições locais do norte de MT, em que manter alta saturação por K no solo provoca lixiviação, devido aos altos índices pluviométricos, principalmente durante o cultivo da soja (novembro a fevereiro) com mais de $1200 \mathrm{~mm}$ de chuva (CAVALLI, 2016).

Além disso, no sistema soja/milho em Mato Grosso, a palhada do milho tem altas quantidades de K que não aparece no resultado de análise de solo, pois as coletas normalmente são feitas após a colheita do milho. Assim há mineralização da palha de milho durante o ciclo da soja o que eleva os teores deste elemento no solo (CAVALLI, 2016). Então deve-se considerar os teores de $\mathrm{K}$ nas palhadas para o cálculo da real saturação por K no sistema (ROSOLEM et al., 2003).

\section{CONCLUSÕES}

A aplicação de fertilizantes ano a ano na mesma linha de semeadura altera a maioria dos atributos químicos no solo, concentrando alguns nutrientes em linha, principalmente o $\mathrm{P}$, que é um fator altamente positivo, pois reduz a fixação deste elemento.

O ponto de coleta da amostra de solo (linha ou entrelinha) no sistema de semeadura direta com linha de fertilização fixa pode alterar os resultados analíticos e a interpretação dos mesmos, inferindo em recomendações equivocadas.

Há acidificação da linha de semeadura pela aplicação de fertilizantes nitrogenados, pela extração/exportação de cátions e pelo balanço eletroquímico que a planta realiza é significativa neste sistema.

\section{AGRADECIMENTOS}

Agradecimento à fazenda Gobbi pelo suporte financeiro e estrutura para condução do trabalho.

\section{REFERÊNCIAS}

CAVALLI, E. Dinâmica do potássio no sistema soja-milho na região médio norte do Mato Grosso. Dissertação (Mestrado em Agronomia) - Universidade Federal de Mato Grosso, Sinop, 2016.

CAVALli, E.; LANGE, A.; CAVALLI, C.; BEHLING, M. Decomposition and release of nutrients from crop residues on soybean-maize cropping systems. Revista brasileira de Ciências Agrarias, Recife, v. 13, n. 2, p. 1-8, 2018. DOI: http://dx.doi.org/10.5039/agraria.v13i2a5527

CFSEMG_COMISSÃO DE FERTILIDADE DO SOLO DO ESTADO DE MINAS GERAIS. Recomendação para o uso de corretivos e fertilizantes em Minas Gerais: $5^{\text {a }}$ Aproximação. Viçosa, MG, 1999.

ELTZ, F. L. F.; PEIXOTO, R. T. G.; JASTER, F. Efeitos de sistemas de preparo do solo nas propriedades físicas e químicas de um Latossolo Bruno Álico. Revista Brasileira de Ciência do Solo, v. 13, n. 2, 259-267, 1989.

FURTINI, A.E.; VALE, F.R.; RESENDE, A.V.; GUILHERME, L.R.G; GUEDES, G. A. Fertilidade do solo. Lavras: UFLA/FAEPE, 2001. 252 p.

GASSO, V.; SØRENSEN, C. A. G.; OUDSHOORN F. W.; GREEN, O. Controlled Traffic Farming: A review of the environmental impacts. European Journal of Agronomy, v. $48, \quad$ p. $66-73, \quad 2013$. DOI: https://dx.doi.org/10.1016/j.eja.2013.02.002

MUZILLI, O. Influência do sistema de plantio direto, comparado ao convencional sobre a fertilidade da camada arável do solo. Revista Brasileira de Ciência do Solo, Campinas, 7:95-102, 1983.

NICOLODI, M.; ANGHINONI, I.; SALET, R.L. Alternativa à coleta de uma secção transversal, com pá de corte, na largura da entrelinha, na amostragem de solo em lavouras com adubação em linha no sistema plantio direto. Revista Plantio Direto, v. 69, p. 22-28, mai./jun. 2002.

ROSOlEM, C. A.; CAlONEGO, J. C.; FOLONI, J. S. S. Lixiviação de potássio da palha de espécies de cobertura de solo de acordo com a quantidade de chuva aplicada. Revista Brasileira de Ciência do Solo, Viçosa, v. 27, p. 355-362, 2003.

RAPER, R. L. Agricultural Traffic Impacts on Soil. Journal of Terramechanics, Oxford, v. 42, n. 3-4, p. 259-280, 2005. DOI: https://doi.org/10.1016/j.jterra.2004.10.010

SÁ, J. C. M. Fósforo: Frações, formas de ocorrência e distribuição no perfil do solo. In: CURSO SOBRE MANEJO DO SOLO NO SISTEMA PLANTIO DIRETO, 1996, Castro. Anais... Castro: Fundação ABC, 1996. p. 229-243.

SOUSA, D. M. G. de; NUNES, R. S.; REIN, T.A.; SANTOS JUNIOR, J. D. G. Manejo da Adubação Fosfatada para Culturas Anuais no Cerrado. Planaltina: Embrapa Cerrados, 2016. 10 p. (Circular Técnica).

VITTI, G. C.; VIEIRA, J. L. In: Encontro Nacional de Plantio Direto na Palha, 15., 2016, Goiânia. Anais... Goiânia: Embrapa/UFG/MAPA, 2016.

ZANDONADI, R. S. Computational Tools for Improving Route Planning in Agricultural Field Operations. 2012. 125f. Dissertação (PhD Biosystems and Agricultural Engineering) - University of Kentucky, Lenxington-KY, 2012. 